\title{
Predictors of quality of life of medical students and a comparison with quality of life of adult health care workers in Thailand
}

\author{
Chaisiri Angkurawaranon ${ }^{*}$ (D) Wichuda Jiraporncharoen ${ }^{1}$, Arty Sachdev², Anawat Wisetborisut ${ }^{1}$, \\ Withita Jangiam ${ }^{1}$ and Ronnaphob Uaphanthasath ${ }^{1}$
}

\begin{abstract}
Introduction: There have been few studies which have compared the quality of life between medical students and adult health care workers.

Aims: (1) To compare health related quality of life (HRQoL) between medical students and adult health care workers and (2) to identify factors associated with quality of life of medical students.

Methods: A cross sectional survey of medical students at Chiang Mai University and health care workers at Chiang Mai University Hospital in 2013.

Results: Compared with the population of adult health care workers, medical students had a higher physical HRQoL but similar mental HRQoL. This is potentially mediated by the presence of depression, as the prevalence of depressive symptoms was similar in both groups. Higher academic achievement and absence of underlying biomedical conditions were associated with higher HRQoL in medical students.
\end{abstract}

Conclusion: The psychological burden for medical students in Thailand could be at similar levels to that of their adult health care counterparts.

Keywords: Quality of life, Medical students, Health care workers, Thailand

\section{Background}

Health related quality of life (HRQoL) is an important health outcome measurement since it assesses health not only on the basis of years living but in terms of quality living (Centers for Disease Control and Prevention 2014). Biological, behavioral, psychological and socioeconomic factors as well as age and gender can influence an individual's level of health related quality of life. However, the relationships between these factors and quality of life can vary in different cultures and populations (Bowling 2005).

\footnotetext{
*Correspondence: chaisiri.a@cmu.ac.th

${ }^{1}$ Department of Family Medicine, Faculty of Medicine, Chiang Mai University, 110 Intawaroros Road, Sriphum, Muang, Chiang Mai 50200, Thailand

Full list of author information is available at the end of the article
}

Medical students are considered to be a high risk population for poor quality of life (McNeill et al. 2014). Various research findings from the past few decades have shown potential negative impacts of attending medical school on student health (Paro et al. 2010; Rosal et al. 1997). Medical students are found to have higher level of overall psychological distress relative to both the general population and age matched peers (Dyrbye et al. 2006). Studying and training in a medical school causes stress from high competition, lack of free time and psychological distress from experiencing illnesses and suffering of patients (Dezee et al. 2012; Rosal et al. 1997). Depression is also a common mental health problem found among medical students but is usually not recognized (Ketumarn et al. 2013). Medical students may view mental illness as a form of weakness therefore resisting medical help (McNeill et al. 2014). All these factors may 
contribute to lower quality of life among medical students (Paro et al. 2010).

Quality of life among medical students has been emphasized as literature has suggested that a lower quality of life is associated with an unhealthy lifestyle, mental health problems and academic failure as well as having a negative impact on professional development (Ibrahim et al. 2014; Rosal et al. 1997).

Previous research from western countries has shown that medical students have lower mental quality of life and more mental illness compared to the general population (Henning et al. 2012; Dyrbye et al. 2014). However, few studies have compared the quality of life between medical students and the adult health care worker population, which is another population documented as having high levels of psychological distress (Wisetborisut et al. 2014; Teles et al. 2014).

This study aims to compare physical and mental health related quality of life between medical students and health care workers and to identify sociodemographic and biomedical factors associated with quality of life among medical students. Assessment and identification of factors associated with quality of life will help guide specific interventions to promote better quality of life and to help prevent deteriorating conditions which may negatively influence the quality of life among medical students.

\section{Methods}

A cross sectional survey was conducted among undergraduate medical students attending Chiang Mai University between March and May 2013. During orientation for the new academic year, students were asked to complete a self-reported questionnaire on demographic factors, underlying medical conditions and quality of life. Students entering the first year of medical school were excluded from the study as they had yet to start medical school. For the comparison population, during the same period, a survey among health care workers working for Chiang Mai University Hospital was also conducted (Angkurawaranon et al. 2014). This health care worker population includes all types of personnel employed by the university hospital which included doctors, dentists, nurses and lab technicians as well as a number of general workers.

\section{Measurement and definitions}

Health related quality of life was measured using the RAND 36-item short form survey (SF-36) (Ware and Sherbourne 1992). It is used to calculate health related quality of life in eight subdomains: physical functioning $(\mathrm{PF})$, bodily pain (BP), role limitations due to physical health problems (RP), role limitations due to personal or emotional problems (RE), mental health/emotional well-being $(\mathrm{MH})$, social function (SF), vitality (VT) and general health perceptions $(\mathrm{GH})$. These eight subdomains can be used to further calculate two main summary measures, the physical component score (PCS) and mental component score (MCS) Higher scores indicate higher health related quality of life. The SF-36 Thai version has been validated and found to be reliable among healthy populations (Lim et al. 2008).

Sociodemographic characteristics of medical students include age, sex, year of medical school, parental occupation, monthly household income, monthly personal expenses and whether they were local to Chiang Mai province. It was an assumption that local students from Chiang Mai province would have stronger social support from their families (Sreeramareddy et al. 2007). Regarding parental occupation, data was dichotomized into whether the student's parents worked in the medical field or not. Evidence has suggested that if the parents were medical doctors the students could have a higher prevalence of psychological morbidity due to higher parental expectations (Sreeramareddy et al. 2007).

Regarding biomedical factors of medical students, both physical health and mental health were considered. For assessment of physical health, students were asked to list their known underlying history of chronic disease. The data were dichotomized into whether or not they had any known underlying chronic disease. Mental health was assessed mental using the Patient Health Questionnaire (PHQ-9). The nine questions of the PHQ-9 are based on the DSM-IV diagnostic criteria for major depression (Kroenke et al. 2001). The cut-off point of nine or more was used to define depression as this has been demonstrated as having good sensitivity and specificity in the Thai population (Lotrakul et al. 2008).

\section{Analysis plan}

The quality of life scores among medical students and health care workers were summarized using descriptive statistics. To compare the quality of life scores between the student population and the adult health worker population, the mean quality of life scores were stratified by gender and tested using $t$ tests. Multivariable analysis adjusted for age, sex and household income and depression was also conducted to explore the difference in QoL scores between medical students and health care workers.

Sociodemographic characteristics and biomedical factors associated with quality of life were analysed using the data collected from medical students using a t test or Chi square test. Any factors potentially associated with quality of life $(\mathrm{p}<0.10)$ were considered for multivariable analyses. To identify the strongest factors associated 
with quality of life in medical students, all potentially significant variables were entered into a multivariable linear regression model. Each variable was then removed one by one, starting with the least significant variable until all remaining variables remained statistically significant $(\mathrm{p}<0.05)$. All analysis was done using Stata Statistical Software: Release 13 (StataCorp.)

\section{Results}

A total of 1014 students participated in this study (68.5\% overall response rate among medical students), $53.1 \%$ (538) of the study participants were female. Almost every medical student started attending the Faculty of Medicine immediately after they graduated from their high school. Only about one medical student per year was a graduate student with a prior bachelor's degree. In the adult health worker population, 3204 participants completed the survey $(59.7 \%$ overall response rate among health care workers at Chiang Mai University Hospital). $77 \%$ of health care workers who participated were female (2472). The average age of the medical students was 20.8 years $(\mathrm{SD}=1.5)$ and for adult health care workers was 40.6 years $(\mathrm{SD}=9.9)($ Table 1$)$.

\section{Comparing the quality of life between medical students and adult health care workers}

Male and female medical students had significantly higher physical quality of life on all subdomains than adult health care workers (Tables 6, 7 of appendix). For male medical students, their average physical component summary score was $90.3(\mathrm{SD}=13.7)$ while the average physical component summary score for their male health care worker counterparts was $74.5(\mathrm{SD}=16.2)$. For female students, their average physical component summary score was $90.7(\mathrm{SD}=10.6)$ compared to 74.8 $(\mathrm{SD}=15.4)$ in adult female health care workers.

However, when mental quality of life was considered, medical students did not seem to have this large advantage. In male subjects, the mental component summary scores for students and workers were quite similar (78.6 vs $77.8, \mathrm{p}=0.31$ ). In female medical students, although students had statistically higher mental component summary scores, the difference was small (80.2 vs 77.8 , $\mathrm{p}<0.01$ ). By considering the four subdomains of mental quality of life individually, a consistent pattern emerged in both men and women. The mean quality of life scores in vitality (VT), role limitations due to emotional problems (RE) and mental health (MH) among medical students were quite similar to their adult counterparts (Table 2). This was also reflected in the prevalence of signs/symptoms of depression. The proportion presenting with such signs/symptoms were similar between male students and adult workers (12.6 vs $11.2, \mathrm{p}=0.52)$ and
Table 1 Demographic of participants

\begin{tabular}{|c|c|c|c|}
\hline \multicolumn{2}{|c|}{$\begin{array}{l}\text { Medial students } \\
\text { at Chiang Mai University }\end{array}$} & \multicolumn{2}{|c|}{$\begin{array}{l}\text { Health care workers }{ }^{\mathrm{a}} \text { at Chiang } \\
\text { Mai University Hospital }\end{array}$} \\
\hline Number & 1014 & Number & 3204 \\
\hline Mean age (SD) & $20.8(1.5)$ & Mean age (SD) & $40.2(10.7)$ \\
\hline \multicolumn{2}{|c|}{ Year of medical school (\%) } & \multicolumn{2}{|l|}{ Age group (\%) } \\
\hline 2nd year & 23.8 & $<30$ & 21.1 \\
\hline 3rd year & 22.0 & $30-40$ & 27.4 \\
\hline 4th year & 21.9 & $40-50$ & 27.3 \\
\hline 5 th year & 13.7 & $>50$ & 24.1 \\
\hline 6th year & 18.6 & & \\
\hline Female (\%) & 53.1 & Female (\%) & 77.1 \\
\hline \multicolumn{2}{|l|}{ Parental occupation ${ }^{\mathrm{b}}(\%)$} & \multicolumn{2}{|l|}{ Job positions ${ }^{\mathrm{b}}(\%)$} \\
\hline Health professionals & 8.3 & Health professionals & 62.9 \\
\hline $\begin{array}{l}\text { Non-health } \\
\text { professionals }\end{array}$ & 90.5 & $\begin{array}{l}\text { Non health } \\
\text { professionals }\end{array}$ & 37.1 \\
\hline Missing & 1.2 & Missing & 0 \\
\hline \multicolumn{2}{|c|}{$\begin{array}{l}\text { Monthly household income } \\
\text { in baht (\%) }\end{array}$} & \multicolumn{2}{|c|}{$\begin{array}{l}\text { Monthly household income } \\
\text { in baht (\%) }\end{array}$} \\
\hline$<30,000$ & 22.3 & $<30,000$ & 54.1 \\
\hline $30,000-60,000$ & 34.6 & $30,000-60,000$ & 28.4 \\
\hline $60,000-90,000$ & 19.7 & $60,000-90,000$ & 9.5 \\
\hline$>90,000$ & 21.0 & $>90,000$ & 8.0 \\
\hline Missing & 2.4 & Missing & 0 \\
\hline
\end{tabular}

a The health care worker population includes all types of personnel employed by the university hospital which included doctors, dentists, nurses and lab technicians as well as a number of general workers

${ }^{\mathrm{b}}$ Health professional include jobs such as doctors, nurses, physiotherapist and pharmacist where these occupations are involve with patient care and have professional licensing bodies; non health profession include jobs such as lawyers, administrative assistants and workers

also between female students and female adult workers (7.4 vs $9.2 \%, p=0.01)$ (Table 2$)$. In the multivariable analysis, additional adjustments for age, sex, household income and depression attenuated the differences in quality of life between medical students and adult health care workers (Table 3).

\section{Factors associated with quality of life among medical students}

The results showed that physical quality of life among both males and females students were high. In terms of the relationships between sociodemographic factors and quality of life, females showed slightly higher mental health related quality of life than males (78.6 vs $80.2, \mathrm{p}=0.04$ ). Increasing years at medical school were significantly associated with higher physical and mental health related quality of life. In the univariable analysis, parental occupation, household income, personal expense, grade point average and having families in Chiang Mai province did not show any significant associations with physical or mental health related quality of life among medical students (Table 4). 
Table 2 Comparison in mental quality of life and prevalence of depression between medical students and health care workers by sex

\begin{tabular}{|c|c|c|c|}
\hline Characteristic & Medical student & Healthcare worker & p value \\
\hline \multicolumn{4}{|l|}{ Men } \\
\hline Number & 476 & 733 & \\
\hline Mean age & $20.9(1.5)$ & $40.6(9.9)$ & $<0.01$ \\
\hline \multicolumn{4}{|l|}{ Mental quality of life } \\
\hline Mental component summary & $78.6(13.1)$ & $77.8(13.8)$ & 0.31 \\
\hline VT/vitality & $68.4(13.9)$ & $70.7(13.5)$ & $<0.01$ \\
\hline SF/social function & $90.2(14.2)$ & $83.4(16.3)$ & $<0.01$ \\
\hline RE/role limitations due to emotional problems & $86.7(28.8)$ & $85.7(30.2)$ & 0.56 \\
\hline $\mathrm{MH} /$ mental health & $76.5(13.6)$ & $76.5(13.4)$ & 0.97 \\
\hline Depression (col \%) & & - & 0.52 \\
\hline None & 87.4 & 88.8 & \\
\hline Mild & 10.7 & 8.9 & \\
\hline Moderate to severe & 1.9 & 2.3 & \\
\hline \multicolumn{4}{|l|}{ Women } \\
\hline Number & 538 & 2471 & \\
\hline Mean age & $20.8(1.5)$ & $40.1(10.9)$ & $<0.01$ \\
\hline \multicolumn{4}{|l|}{ Mental quality of life } \\
\hline Mental component summary & $80.2(11.4)$ & $77.8(13.2)$ & $<0.01$ \\
\hline VT, vitality & $69.8(11.6)$ & $68.8(13.3)$ & 0.12 \\
\hline SF/social function & $91.5(13.6)$ & $85.3(15.8)$ & $<0.01$ \\
\hline RE/role limitations due to emotional problems & $89.7(24.3)$ & $87.1(27.4)$ & 0.04 \\
\hline $\mathrm{MH} /$ mental health & $78.2(11.5)$ & $76.2(13.2)$ & $<0.01$ \\
\hline Depression (col \%) & & & 0.01 \\
\hline None & 92.2 & 90.7 & \\
\hline Mild & 6.3 & 8.0 & \\
\hline Moderate to severe & 1.1 & 1.2 & \\
\hline
\end{tabular}

Table 3 Differences in mental quality of life between medical students and health care workers

\begin{tabular}{|c|c|c|c|}
\hline \multirow[t]{2}{*}{ Mental quality of life (QoL) } & \multicolumn{3}{|c|}{ Mean differences in QoL score (students-workers) } \\
\hline & Model 1 & Model 2 & Model 2 \\
\hline Mental component summary & $1.68(0.76-2.50)$ & $1.74(0.38-3.11)$ & $1.22(0.01-2.44)$ \\
\hline VT/vitality & $-0.12(-1.06$ to 0.81$)$ & $1.07(-0.31$ to 2.44$)$ & $0.65(-0.64$ to 1.93$)$ \\
\hline SF/social function & $5.98(4.90-7.08)$ & $4.87(3.27-6.48)$ & $4.40(2.90-5.90)$ \\
\hline RE/role limitations due to emotional problems & $1.52(-0.44$ to 3.48$)$ & $1.19(-1.70$ to 4.08$)$ & $0.44(-2.30$ to 3.18$)$ \\
\hline $\mathrm{MH} /$ mental health & $1.13(0.21-2.06)$ & $1.02(-0.34$ to 2.39$)$ & $0.53(-0.71$ to 1.78$)$ \\
\hline
\end{tabular}

Model 1: Adjusted for age and sex

Model 2: Adjusted for age, sex and household income

Model 3: Adjusted for age, sex, household income and depression

For associations between biomedical factors and quality of life, underlying medical and mental conditions were each significantly associated with quality of life. The results showed that students with reported underlying diseases showed slightly lower physical and mental health related quality of life than students who had not reported any underlying disease. As expected, students with signs and symptoms of depression also showed much lower physical and mental health related quality of life compared to those without (Table 4).

The multivariable analysis showed that in addition to year of medical school, self reported underlying disease, depression and GPA were each independently associated with physical health related quality of life among medical students (Table 8 of appendix). As regards mental quality of life, only year of medical 
Table 4 Factors associated with quality of life among medical students

\begin{tabular}{|c|c|c|c|c|c|c|}
\hline & Number & $\%$ & Physical QoL (SD) & $\mathrm{p}$ value & Mental QoL (SD) & p value \\
\hline Sex & & & & 0.59 & & 0.04 \\
\hline Male & 476 & 46.9 & $90.3(13.7)$ & & $78.6(13.1)$ & \\
\hline Female & 538 & 53.1 & 90.7 (10.6) & & $80.2(11.3)$ & \\
\hline Year of medical school & & & & $<0.01$ & & $<0.01$ \\
\hline 2nd year & 241 & 23.8 & $87.5(12.1)$ & & $77.1(12.8)$ & \\
\hline 3rd year & 223 & 22.0 & $89.5(14.0)$ & & $79.1(12.3)$ & \\
\hline 4th year & 222 & 21.9 & $92.0(11.4)$ & & $79.5(12.5)$ & \\
\hline 5 th year & 139 & 13.7 & $92.8(11.1)$ & & $83.4(10.9)$ & \\
\hline 6th year & 189 & 18.6 & $92.1(10.6)$ & & $79.8(11.1)$ & \\
\hline Parental occupation & & & & 0.57 & & 0.99 \\
\hline None medical field & 918 & 90.5 & $90.5(12.2)$ & & $79.5(12.2)$ & \\
\hline Medical field & 84 & 8.3 & $91.3(9.5)$ & & 79.5 (11.8) & \\
\hline Missing & 12 & 1.2 & - & & - & \\
\hline Household income & & & & 0.09 & & 0.71 \\
\hline$<30,000$ & 226 & 22.3 & $90.6(12.2)$ & & 78.7 (12.9) & \\
\hline $30,000-60,000$ & 351 & 34.6 & $89.2(13.3)$ & & $79.6(11.1)$ & \\
\hline $60,000-90,000$ & 200 & 19.7 & $91.2(10.8)$ & & $79.5(11.5)$ & \\
\hline$>90,000$ & 213 & 21.0 & $91.7(11.4)$ & & $80.0(14.0)$ & \\
\hline Missing & 24 & 2.4 & - & & - & \\
\hline Personal expense & & & & 0.43 & & 0.31 \\
\hline$<3000$ & 209 & 20.6 & $89.5(12.3)$ & & $78.9(12.9)$ & \\
\hline $3000-6000$ & 524 & 51.7 & $91.0(11.5)$ & & $79.8(11.4)$ & \\
\hline $6000-9000$ & 152 & 15.0 & $90.6(12.6)$ & & $80.1(13.1)$ & \\
\hline$>9000$ & 120 & 11.8 & $89.7(14.4)$ & & $77.7(13.2)$ & \\
\hline Missing & 9 & 0.9 & - & & & \\
\hline Residence & & & & 0.71 & & 0.51 \\
\hline Chiang Mai & 290 & 28.6 & $90.7(11.7)$ & & $79.8(12.2)$ & \\
\hline Outside Chiang Mai & 724 & 71.4 & $90.4(12.3)$ & & $79.3(12.2)$ & \\
\hline Grade point average (GPA) & & & & 0.18 & & 0.71 \\
\hline$<3.0$ & 336 & 33.1 & $89.7(14.3)$ & & $79.6(12.6)$ & \\
\hline $3.0-3.5$ & 343 & 33.8 & $91.4(11.0)$ & & 79.7 (11.9) & \\
\hline$>3.5$ & 335 & 33.0 & $90.4(10.9)$ & & $79.0(12.1)$ & \\
\hline Body mass index (BMI) & & & & 0.43 & & 0.51 \\
\hline Underweight: $<18 \mathrm{~kg} / \mathrm{m}^{2}$ & 96 & 9.5 & $89.5(13.4)$ & & $79.6(12.2)$ & \\
\hline Normal: $18-25 \mathrm{~kg} / \mathrm{m}^{2}$ & 721 & 71.1 & $91.1(11.2)$ & & $79.6(12.1)$ & \\
\hline Obese: $\geq 25 \mathrm{~kg} / \mathrm{m}^{2}$ & 86 & 8.5 & $90.9(10.7)$ & & $81.2(10.8)$ & \\
\hline Missing & 111 & 10.9 & & & & \\
\hline Self report underlying disease & & & & $<0.01$ & & 0.04 \\
\hline No & 828 & 81.7 & $91.3(11.2)$ & & $79.8(12.0)$ & \\
\hline Yes & 186 & 18.3 & $87.0(15.2)$ & & $77.8(13.0)$ & \\
\hline Depression & & & & $<0.01$ & & $<0.01$ \\
\hline No & 912 & 89.9 & $91.7(10.6)$ & & $81.1(10.3)$ & \\
\hline Mild & 85 & 8.4 & $81.5(18.3)$ & & $68.2(14.8)$ & \\
\hline Moderate to severe & 15 & 1.5 & $71.4(19.4)$ & & $43.9(11.6)$ & \\
\hline Missing & 2 & 0.2 & - & & - & \\
\hline
\end{tabular}

school and having signs/symptoms of depression were independent factors in the multivariable analysis. Increasing year of medical school was associated with higher mental quality of life, while signs/symptoms of depression were associated with lower mental quality of life (Table 5). 
Table 5 Factors associated with mental quality of life among medical students using multivariable linear regression

\begin{tabular}{|c|c|c|c|}
\hline & $\begin{array}{l}\text { Regression } \\
\text { coefficient ( } \beta \text { ) }\end{array}$ & $\begin{array}{l}95 \% \text { confidence } \\
\text { interval }\end{array}$ & $\mathrm{p}$ value \\
\hline \multicolumn{4}{|l|}{ Mental quality of life } \\
\hline $\begin{array}{l}\text { Year of medical } \\
\text { school }\end{array}$ & & & $0.01^{\#}$ \\
\hline 2nd year & Reference & & \\
\hline 3rd year & 1.06 & -0.91 to 3.02 & 0.29 \\
\hline 4th year & 1.12 & -0.84 to 3.10 & 0.26 \\
\hline 5th year & 4.37 & 2.11 to 6.64 & $<0.01$ \\
\hline 6th year & 1.56 & -0.49 to 3.61 & 0.14 \\
\hline Depression & & & $<0.01^{\#}$ \\
\hline No & Reference & & \\
\hline Mild & -12.63 & -15.01 to -10.23 & $<0.01$ \\
\hline Moderate to severe & -36.31 & -41.82 to -30.78 & $<0.01$ \\
\hline
\end{tabular}

\# p value for trend

\section{Discussion}

The study demonstrated that in comparison with an adult health care worker population, medical students had a higher physical HRQoL but a similar mental HRQoL. Among medical students, the higher the academic year in medical school the greater the association with higher physical and mental HRQoL. Higher GPA and absence of underlying medical conditions were associated with higher physical HRQoL while signs and symptoms of depression were associated with lower physical and mental HRQoL.

The identification of the trend that medical students have a higher physical QoL than adult health care workers was expected due to the higher risk of morbidities associated with increasing age (Rusli et al. 2008). However, similar levels in mental quality of life between medical students and adult health care personnel could be a potential issue that needs further research. In most subdomains of mental QoL, the QoL scores were similar between groups. This is perhaps mediated by the presence of depression, as the prevalence of depressive symptoms was similar in both groups. The results of this study also support this hypothesis as additional adjustment for depression diluted the differences in quality of life between students and workers. It is usually expected that given a similar setting and environment, mental HRQol of young adults would usually be better than their older adult counterparts (Rustoen et al. 2005; Jorngarden et al. 2006). These results suggested that the level of psychological burden on medical students could be similar to that of their adult health care counterpart.
As for factors associated with quality of life among medical students, many studies have reported that HRQoL of medical students can vary by class year (Sreeramareddy et al. 2007; Rosal et al. 1997). However, trends in associations seem to differ between settings. Literature suggested that attending medical school has a major negative impact during later clinical years as the students have to make contact with patients and this may lead to intense emotional experiences, increasing levels of stress and depression (Paro et al. 2010; Dyrbye et al. 2006). Other studies, however, have suggested that there was no significant difference from year to year (Sreeramareddy et al. 2007; Tempski et al. 2012). This study found that a higher academic year in medical school was associated with higher mental and physical HRQoL. This is consistent with the findings from a study conducted in Pakistan, which suggested that exposure to more real life situations in later clinical years may help students develop and improve coping strategies while the fear of examinations becomes somewhat subdued because of their past experience with them (Naseem and Iqbal 2010). The study also found that a higher GPA was associated with higher QoL. Reverse causation may play a role in this observed association as studies have suggested that students with a higher HRQol usually perform better academically (Hettiarachchi et al. 2014).

The study found that physical and psychological morbidities, particularly depression, were associated with lower QoL in medical students. This is supported by previous literature where chronic health problems and depressive symptoms were associated with lower HRQoL (Paro et al. 2010; Michelson et al. 2000). For decades it has been documented that depression is a common mental health problem among medical students which can affect the student's performance as well as personal and professional development (Paro et al. 2010; Rosal et al. 1997; McNeill et al. 2014).

The study had several limitations. The study was cross sectional, thus causal relationships could not be demonstrated between the associations seen. Underlying causes and issues on why medical students may have high levels of psychological burden need to be further explored. The study achieved a high response rate to the surveys but the findings may not be entirely generalizable to other medical students in different settings due to sociocultural variations, different ethnic populations, different curriculums and entry route of medical students. Most of the medical students in Thailand attend medical school directly after completion of high school and all are Thais.

Despite its limitations, the study provides some insight into physical and mental HRQoL of medical students and their associated factors. The psychological burden of medical students in Thailand could be similar to that 
of their adult health care counterpart, which is already considered a population exposed to high levels of stress (Ruotsalainen et al. 2014). Despite the diversity between settings, the overall HRQoL and the proportion of medical student with depression in the study are comparable with other previous reports (Paro et al. 2010; Dyrbye et al. 2006) These findings suggest that specific preventative measures should be considered by both the Thai educational council and medical schools to improve mental HRQoL among medical students. The measures could potentially include changes in the curriculum towards more problem-based and self directed learning (Wilson et al. 1996). Interventions to improve overall mental health and develop student resilience such as group discussion, enhancing relationships between students and teachers, lectures on stress and time management may be helpful. Counseling services have been found to be effective in reducing psychological stress in some similar cases (Sharif and Armitage 2004; Velayudhan et al. 2010).

An example of a comprehensive program to improve medical students' resilience and health in Australia is describe by Hassed et al. (2008). The interventions were based on the ESSENCE lifestyle model (Hassed 2005) which focuses on important factors such as stress management, mindfulness practice, proper exercise and healthy diets. The interventions were delivered through lectures and group discussions. Core skills and contents were assessed while students were also encouraged to maintain personal practices by keeping journals. The concepts described in the ESSENCE model have been applied in Chiang Mai University Medical School since 2010. During orientation of the new school year, students undergo the Medical Student Healthy Day activities which include taking a physical examination and a physical fitness test. Anonymized data is also collected on diet, physical activity level, smoking, alcohol use and sexual behavior. This is then used to plan population level interventions to reduce risky behaviors among medical students. However, maintaining healthy behavior and practices among medical students remains a challenging issue and one initiative, the Medical Student Healthy Day activities, has not yet been formally assessed. Nonetheless, it has been noted that the distress among physicians usually has its origins in medical school (Dyrbye et al. 2006). Therefore, such measures and interventions in this period may help prevent and reduce suffering from mental illness in medical students, improve their mental HRQoL and enable them to have better performance as well as enhance personal and professional development.

\section{Authors' contributions}

$C A, W J$ and $A S$ conceived the study. CA, WJ, AW, RU were involved in data collection. CA, WJ and AS analyzed the data and wrote the first draft. All authors read and approved the final manuscript.

\section{Author details}

${ }^{1}$ Department of Family Medicine, Faculty of Medicine, Chiang Mai University, 110 Intawaroros Road, Sriphum, Muang, Chiang Mai 50200, Thailand. ${ }^{2}$ Chiang Mai Medical Center Hospital, 21 Nuntaram Road, Haiya, Muang, Chiang Mai 50100, Thailand.

\section{Acknowledgements}

We would like to thank the Student Affairs Section and Health promotion Unit Faculty of Medicine, Chiang Mai University for their help with data collection.

Competing interests

The authors declare that they have no competing interests.

Ethical approval

Both surveys were granted ethical approval by the Faculty of Medicine, Chiang Mai University (Reference numbers 069/2012 and FAM-2577-02093).

Funding/support

The Chiang Mai University Health worker was funded by the Faculty of Medicine Research Fund of Chiang Mai University. The funders had no roles in study design, analysis, preparation of manuscript and decision to publish.

\section{Appendix}

See Tables 6, 7 and 8.

Table 6 Comparison in physical quality of life between medical students and health care workers by sex

\begin{tabular}{|c|c|c|c|}
\hline Characteristic & $\begin{array}{l}\text { Medical student } \\
(n=476)\end{array}$ & $\begin{array}{l}\text { Healthcare } \\
\text { worker }(n=733)\end{array}$ & p value \\
\hline \multicolumn{4}{|l|}{ Men } \\
\hline \multicolumn{4}{|c|}{ Physical quality of life } \\
\hline $\begin{array}{l}\text { Physical compo- } \\
\text { nent summery }\end{array}$ & $90.3(13.7)$ & 74.5 (16.2) & $<0.01$ \\
\hline BP/bodily pain & $84.1(18.0)$ & $74.2(18.2)$ & $<0.01$ \\
\hline $\begin{array}{l}\text { PF/physical } \\
\text { function }\end{array}$ & $90.5(15.1)$ & 75.8 (20.9) & $<0.01$ \\
\hline $\begin{array}{l}\text { RP/role limita- } \\
\text { tions due } \\
\text { to physical } \\
\text { problems }\end{array}$ & $91.7(21.8)$ & 84.4 (29.7) & $<0.01$ \\
\hline $\begin{array}{l}\text { GH/general } \\
\text { health }\end{array}$ & 73.5 (17.3) & $65.8(16.5)$ & $<0.01$ \\
\hline Characteristic & $\begin{array}{l}\text { Medical student } \\
(n=538)\end{array}$ & $\begin{array}{l}\text { Healthcare worker } \\
(n=2471)\end{array}$ & p value \\
\hline
\end{tabular}

\begin{tabular}{|c|c|c|c|}
\hline \multicolumn{4}{|l|}{ Women } \\
\hline \multicolumn{4}{|c|}{ Physical quality of life } \\
\hline $\begin{array}{l}\text { Physical com- } \\
\text { poenet sum- } \\
\text { mery }\end{array}$ & 90.7 (10.6) & $74.8(15.4)$ & $<0.01$ \\
\hline BP/bodily pain & $83.3(16.8)$ & $72.8(19.2)$ & $<0.01$ \\
\hline $\begin{array}{l}\text { PF/physical } \\
\text { function }\end{array}$ & $90.2(12.9)$ & 76.6 (18.9) & $<0.01$ \\
\hline $\begin{array}{l}\text { RP/role limita- } \\
\text { tions due } \\
\text { to physical } \\
\text { problems }\end{array}$ & $94.1(18.2)$ & $86.4(27.9)$ & $<0.01$ \\
\hline $\begin{array}{l}\text { GH/general } \\
\text { health }\end{array}$ & $73.2(15.8)$ & $64.5(16.7)$ & $<0.01$ \\
\hline
\end{tabular}


Table 7 Differences in physical quality of life between medical students and health care workers

\begin{tabular}{llll}
\hline $\begin{array}{l}\text { Physical quality } \\
\text { of life (QoL) }\end{array}$ & \multicolumn{4}{l}{ Mean differences in QoL score (students-workers) } \\
\cline { 2 - 4 } & Model 1 & Model 2 & Model 2 \\
\hline $\begin{array}{c}\text { Physical compo- } \\
\text { nent summery }\end{array}$ & $15.8(14.7-16.8)$ & $8.42(6.91-9.94)$ & $8.00(6.56-9.43)$ \\
BP/bodily pain & $10.6(9.01-11.9)$ & $7.15(5.21-9.08)$ & $6.74(4.86-8.63)$ \\
$\begin{array}{c}\text { PF/physical } \\
\text { function }\end{array}$ & $13.9(12.6-15.2)$ & $2.32(0.58-4.16)$ & $1.98(0.17-3.78)$ \\
$\begin{array}{c}\text { RP/role limita- } \\
\text { tions due } \\
\text { to physical }\end{array}$ & $6.99(5.12-8.87)$ & $0.62(-2.13$ to & $-0.03(-2.70$ to \\
problems & & $3.38)$ & $2.62)$ \\
$\begin{array}{c}\text { GH/general } \\
\text { health }\end{array}$ & $8.51(7.34-9.69)$ & $5.99(4.25-7.72)$ & $5.56(3.91-7.22)$ \\
& & &
\end{tabular}

Model 1: Adjusted for age and sex

Model 2: Adjusted for age, sex and household income

Model 2: Adjusted for age, sex, household income and depression

Table 8 Factors associated with physical quality of life among medical students using multivariable linear regression

\begin{tabular}{lllr}
\hline & $\begin{array}{l}\text { Regression coef- } \\
\text { ficient ( } \boldsymbol{\beta} \text { ) }\end{array}$ & $\begin{array}{l}\text { 95\% confidence } \\
\text { interval }\end{array}$ & p value \\
\hline $\begin{array}{l}\text { Physical quality of life } \\
\text { Year of medical school }\end{array}$ & & & $<0.01^{\#}$ \\
2nd year & Reference & & \\
3rd year & 2.80 & $0.58-5.01$ & 0.01 \\
4th year & 4.92 & $2.69-7.15$ & $<0.01$ \\
5th year & 5.36 & $2.80-7.92$ & $<0.01$ \\
6th year & 5.20 & $2.83-7.57$ & $<0.01$ \\
GPA & & & $0.02^{\#}$ \\
$<3.0$ & Reference & & \\
3.0-3.5 & 1.87 & $0.10-0.64$ & 0.04 \\
$>3.5$ & 2.65 & $0.70-4.59$ & 0.01 \\
Self report underlying & & & \\
disease & & & $<0.01$ \\
No & Reference & & $<0.01^{\#}$ \\
Yes & -3.68 & $-5.51-1.85$ & \\
Depression & & & $<0.01$ \\
No & Reference & & \\
Mild & -9.39 & $-11.94-6.83$ & \\
Moderate to severe & -18.14 & $-24.00-12.28$ & $<0.01$ \\
\hline
\end{tabular}

\# p value for trend

Received: 15 August 2015 Accepted: 3 May 2016

Published online: 10 May 2016

\section{References}

Angkurawaranon C, Wisetborisut A, Jiraporncharoen W, Likhitsathian

S, Uaphanthasath R, Gomutbutra P, Jiraniramai S, Lerssrimonkol C,
Aramrattanna A, Doyle P (2014) Chiang Mai University health Worker study aiming toward a better understanding of noncommunicable disease development in Thailand: methods and description of study population. Clin Epidemiol 6:277

Bowling A (2005) Concepts of functioning, health, well-being and quality of life. In: Measuring health, 3rd edn. McGraw-Hill, New York

Centers for Disease Control and Prevention Health Related Quality of Life. http://www.cdc.gov/hrqol/concept.html. Accessed 26 August 2014

Dezee KJ, Corriere MD, Chronister SM, Durning SJ, Hemann B, Kelly W, Hanson JL, Hemmer PA, Maurer D (2012) What does a good lifestyle mean to you? Perspectives of 4th-year US medical students with military service obligations in 2009. Teach Learn Med 24(4):292-297

Dyrbye LN, Thomas MR, Shanafelt TD (2006) Systematic review of depression, anxiety, and other indicators of psychological distress among US and Canadian medical students. Acad Med 81(4):354-373

Dyrbye LN, West CP, Satele D, Boone S, Tan L, Sloan J, Shanafelt TD (2014) Burnout among US medical students, residents, and early career physicians relative to the general US population. Acad Med 89(3):443-451

Hassed C (2005) The ESSENCE of health care. Aust Fam Physician 34(11):957-960

Hassed C, Lisle S, Sullivan G, Pier C (2008) Enhancing the health of medical students: outcomes of an integrated mindfulness and lifestyle program. Adv Health Sci Educ 14(3):387-398. doi:10.1007/s10459-008-9125-3

Henning MA, Krägeloh CU, Hawken SJ, Zhao Y, Doherty I (2012) The quality of life of medical students studying in New Zealand: a comparison with nonmedical students and a general population reference group. Teach Learn Med 24(4):334-340

Hettiarachchi M, Fonseka CL, Gunasekara P, Jayasinghe P, Maduranga D (2014) How does the quality of life and the underlying biochemical indicators correlate with the performance in academic examinations in a group of medical students of Sri Lanka? Med Educ Online 19:22772. doi:10.3402/ meo.v19.22772

Ibrahim NK, Mahnashi M, Al-Dhahri A, Al-Zahrani B, Al-Wadie E, Aljabri M, Al-Shanketi R, Al-Shehri R, Al-Sayes FM, Bashawari J (2014) Risk factors of coronary heart disease among medical students in King Abdulaziz University, Jeddah, Saudi Arabia. BMC Public Health 14(1):411

Jorngarden A, Wettergen L, von Essen L (2006) Measuring health-related quality of life in adolescents and young adults: Swedish normative data for the SF-36 and the HADS, and the influence of age, gender, and method of administration. Health Qual Life Outcomes 4(1):91

Ketumarn P, Sitdhiraksa N, Sittironnarit G, Limsricharoen K, Pukrittayakamee P. Wannarit K (2013) Psychiatric disorders and personality problems in medical students at Faculty of Medicine, Siriraj Hospital, Years 1982-2007. J Psychiatr Assoc Thailand 57(4):427-438

Kroenke K, Spitzer RL, Williams JB (2001) The Phq-9. J Gen Intern Med 16(9):606-613

Lim L, S-a Seubsman, Sleigh A (2008) Thai SF-36 health survey: tests of data quality, scaling assumptions, reliability and validity in healthy men and women. Health Qual Life Outcomes 6(1):52

Lotrakul M, Sumrithe S, Saipanish R (2008) Reliability and validity of the Thai version of the PHQ-9. BMC Psychiatry 8(1):46

McNeill KG, Kerr A, Mavor KI (2014) Identity and norms: the role of group membership in medical student wellbeing. Perspect Med Educ 3(2):101-112. doi:10.1007/s40037-013-0102-z

Michelson H, Bolund C, Brandberg Y (2000) Multiple chronic health problems are negatively associated with health related quality of life (HRQoL) irrespective of age. Qual Life Res 9(10):1093-1104

Naseem K, Iqbal M (2010) Health related quality of life in a Pakistani medical school. Rawal Med J 35(2):234-237

Paro HB, Morales NM, Silva CH, Rezende CH, Pinto RM, Morales RR, Mendonca TM, Prado MM (2010) Health-related quality of life of medical students. Med Educ 44(3):227-235. doi:10.1111/j.1365-2923.2009.03587.x

Rosal MC, Ockene IS, Ockene JK, Barrett SV, Ma Y, Hebert JR (1997) A longitudinal study of students' depression at one medical school. Acad Med 72(6):542-546

Ruotsalainen JH, Verbeek JH, Mariné A, Serra C (2014) Preventing occupational stress in healthcare workers. Cochrane Database Syst Rev. doi:10.1002/14651858.CD002892.pub4

Rusli BN, Edimansyah BA, Naing L (2008) Working conditions, self-perceived stress, anxiety, depression and quality of life: a structural equation modelling approach. BMC Public Health 8:48. doi:10.1186/1471-2458-8-48 
Rustoen T, Wahl AK, Hanestad BR, Lerdal A, Paul S, Miaskowski C (2005) Age and the experience of chronic pain: differences in health and quality of life among younger, middle-aged, and older adults. Clin J Pain 21(6):513-523

Sharif F, Armitage P (2004) The effect of psychological and educational counselling in reducing anxiety in nursing students. J Psychiatr Ment Health Nurs 11(4):386-392. doi:10.1111/j.1365-2850.2003.00720.x

Sreeramareddy CT, Shankar PR, Binu VS, Mukhopadhyay C, Ray B, Menezes RG (2007) Psychological morbidity, sources of stress and coping strategies among undergraduate medical students of Nepal. BMC Med Educ 7:26. doi:10.1186/1472-6920-7-26

Teles MA, Barbosa M, Vargas AM, Gomes V, Ferreira E, Martins AMEdBL, Ferreira $R$ (2014) Psychosocial work conditions and quality of life among primary health care employees: a cross sectional study. Health Qual Life Outcomes 12(1):72
Tempski P, Bellodi P, Paro H, Enns S, Martins M, Schraiber L (2012) What do medical students think about their quality of life? A qualitative study. BMC Med Educ 12(1):106

Velayudhan A, Gayatridevi S, Bhattacharjee RR (2010) Efficacy of behavioral intervention in reducing anxiety and depression among medical students. Ind Psychiatry J 19(1):41-46. doi:10.4103/0972-6748.77636

Ware JE Jr, Sherbourne CD (1992) The MOS 36-item short-form health survey (SF-36). I. Conceptual framework and item selection. Med Care 30(6):473-483

Wilson JF, Johnson MM, Studts JL, Elam CL (1996) Students' quality of life after a major curriculum change. Acad Med 71(10):S40-\$42

Wisetborisut A, Angkurawaranon C, Jiraporncharoen W, Uaphanthasath R, Wiwatanadate P (2014) Shift work and burnout among health care workers. Occup Med 64(4):279-286. doi:10.1093/occmed/kqu009

\section{Submit your manuscript to a SpringerOpen ${ }^{\circ}$ journal and benefit from:}

- Convenient online submission

- Rigorous peer review

- Immediate publication on acceptance

- Open access: articles freely available online

- High visibility within the field

- Retaining the copyright to your article 